\title{
Involvement of Clinical Medical Professionals as Technical Advisors in Biomedical Engineering Design Projects
}

\author{
Monica A. Schmidt, Richard Jendrucko, and Anthony E. English \\ Biomedical Engineering Program, The University of Tennessee, Knoxville
}

\begin{abstract}
$\underline{\text { Introduction }}$
A new two-semester senior design course sequence has been developed as part of the undergraduate Biomedical Engineering (BME) degree program begun in 2000. These design courses satisfy much of the ABET 2000 Criterion 4 for the Professional Component - specifically the major design experience. The course format involves multiple student teams working on unrelated design projects, so that students can be assigned to projects related to their technical interests. A faculty member and one or more technical advisors direct each project team. Clinical medical professionals have volunteered as technical advisors for design teams in the first two academic years of offering these design courses.
\end{abstract}

Projects involving doctors in clinical practice provided real-world design experiences for BME students. Medical professionals have included an orthopedic surgeon and a neurosurgeon, both in clinical practice at local hospitals, as well as a veterinary orthopedic surgeon from the UT College of Veterinary Medicine. Projects developed with these surgeons include instrumentation design for both unicompartmental and total knee replacement surgery, design of a cranioplasty implant, design of a video system for measurement of canine stride length, and design of a pedaled cart for canine passive motion therapy.

\section{Design Course Format}

The senior design course sequence is taught as two courses, totaling 6 credit hours, taken in sequence during the Fall and Spring semesters of a single academic year. Each course is taught by one to three faculty members, so that each faculty supervises two to four design teams. These entire faculty are involved in grading for each design team's major assignments. Each design team works on a separate project throughout the two semesters of coursework. Thus, multiple projects cover the broad range of technical interests among the BME faculty and students.

Design projects are completed by students working in teams under the supervision of BME faculty with input from technical advisors. Each design team consists of four to five students and receives project guidance from one faculty instructor as well as from one or more technical advisors. The technical advisors may be other faculty, typically within the Mechanical, Aerospace and Biomedical Engineering department, or professionals from outside the University, such as doctors in clinical practice. Faculty instructors have responsibility for assignments and grading, but technical advisors typically review written reports and can provide input to faculty for grading students on their teams.

Students give input on their preferences for design projects, but faculty make the final team assignments. Faculty identify options for design projects prior to the beginning of the Fall semester. At the first class meeting, students are presented with the design project options and then 
surveyed to identify their interests in specific projects and to list their elective courses. Required pre- or corequisite courses include Biomaterials, Biomechanics, and the BME Laboratory. Instructors then divide the students into design teams, based on student interests and elective courses, academic performance, and other considerations.

In the Fall semester, each design team develops its problem statement and specifications, then presents an oral proposal for its design project. The team compiles and reviews background information, develops and evaluates alternatives, selects the best alternative, and begins preliminary design work. Written progress reports are submitted about every two weeks. At the end of the semester, each team makes an oral presentation and submits a written design report. Lectures and other homework assignments cover general design topics such as problem definition, teamwork, sources of information, project management, evaluation of alternatives, engineering economy, legal and ethical issues, materials of construction, risk, reliability and safety.

In the Spring semester, each design team completes the detailed design of its chosen alternative, prepares engineering drawings, then fabricates and tests a prototype of its product or system. Written progress reports are submitted about every two weeks. At the end of the semester, each team makes a final oral presentation and submits its final written design report summarizing the results of both semesters' work.

The senior design courses satisfy the ABET Criterion 4 (Professional Component) requirements of a major design experience in engineering education. Criterion 4 states that the degree program culminates "in a major design experience based on the knowledge and skills acquired in earlier coursework and incorporating engineering standards and realistic constraints that include most of the following considerations: economic, environmental, sustainability, manufacturability, ethical, health and safety, social, and political."1 Engineering standards and the realistic constraints listed previously are addressed in the design projects and must be included in the written design reports. Many of these topics are addressed in design lectures or in the senior seminar course.

\section{Clinical Medical Professionals as Technical Advisors}

Three clinical medical professionals have volunteered as technical advisors for senior design projects. They were recruited through existing professional and personal contacts with BME faculty teaching senior design. Two are surgeons in clinical practice: one practices orthopedics, and the other practices neurosurgery. The third is a veterinary orthopedic surgeon at the UT College of Veterinary Medicine. The orthopedic surgeon and the veterinary orthopedic surgeon have volunteered as technical advisors for two academic years. None were financially compensated by the BME program for their work with the student design teams.

The technical advisors were helpful in recommending possible BME design projects. In most cases they already had projects that they wanted to pursue and develop, but could use support from BME students for design, fabrication, and testing. In other cases, project ideas were developed as a result of discussions with BME faculty. Some projects were supported by financial resources from the technical advisor; others received indirect support such as training, materials, and testing equipment through industrial contacts of the technical advisor. This year one project obtained a grant from industry following a contact made through the technical advisor. 


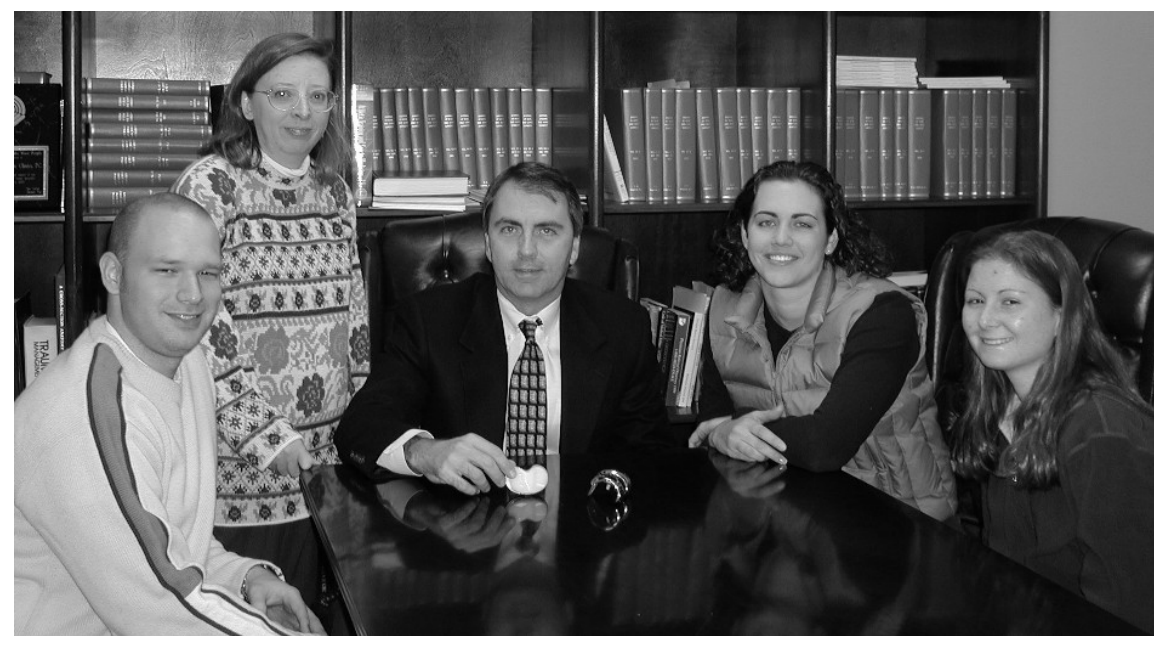

Figure 1. The orthopedic surgeon, Dr. Cates, met with the BME design team and Dr. Schmidt.

The basic responsibility of the technical advisor was to provide guidance and clinical information to the students. Students met with their technical advisor for at least an hour once a month. Meetings were held on campus or at the office or hospital of the medical professional (see Figure 1). The technical advisor provided information on the nature of the design problem, often gave the students initial references to review, explained clinical issues related to the design problem, and provided feedback on preliminary alternatives and designs. Often the advisor was involved in testing of the fabricated prototypes, either by providing facilities and equipment for testing or by participating in the actual testing with the students.

Technical advisors did not have direct responsibility for evaluating student performance, i.e. grading, but they did review student work. Their feedback was requested by the faculty supervising the student teams, and was considered in determining student grades. Design team assignments including progress reports, oral presentations, and written design reports were provided to the technical advisors for their review. The technical advisors were invited to attend oral presentations made by the student teams, but rarely attended due to their clinical schedules.

The first contribution of clinical professionals was the motivation they gave to BME students to put extra effort into the design projects. Students were enthusiastic to learn about real-world problems in clinical medicine, particularly if they wished to work on a project with a doctor. Usually the students on these teams dealt with some inconveniences, such as meeting off-campus (in the doctor's office or hospital) or meeting early in the morning. However, working with doctors significantly increased the students' understanding of medical issues. This motivated them to do more in-depth literature reviews, ask more questions, consider more issues in evaluating alternatives, and put more effort into fabricating and testing their prototypes. This motivation also helped students overcome obstacles such as schedule conflicts and personality differences between team members.

The second contribution of the medical professionals was the clinical resources that were provided through their assistance. These resources were not available through the engineering program. Such resources included opportunities to observe orthopedic surgery and to simulate surgeries using sawbones, and access to animals for prototype testing of veterinary design projects. Tangible resources included videos and training materials, literature and information from medi- 
cal product manufacturers, and examples of medical products to measure or test (including materials for manufacturing prototype designs).

The third contribution was the real-world feedback provided on design concepts — giving students practical understanding of the clinical issues that must be addressed separately from the engineering issues. This feedback was invaluable to the students' development of BME design skills. These clinical issues also related closely to the "realistic constraints" specified in ABET Criterion 4 for the major design experience. Examples of clinical issues included the surgery time required for application of a newly designed instrument or implant, sterilization techniques for a new product, cost/economics (i.e. insurance reimbursement limits, pet owners expenses), training requirements for surgeons using new devices or techniques, and weight limits (from OSHA) for trays of surgical instruments.

The technical advisors identified several benefits that they received from working with BME students on the senior design projects. Medical professionals gained access to engineering professionals' expertise to work on solving real-world clinical problems. Engineers perceived clinical problems and issues from a different perspective than medical professionals, leading to new ways of defining and solving the problems. Engineers had the skills to design and build equipment that could be tested in clinical settings. Working on design projects with engineering students helped the advisors keep up with state-of-the-art technology in their medical fields.

Projects were technically and intellectually stimulating, and had the potential to advance knowledge in the field. The investigative aspect of the design process was challenging. Teaching and mentoring of university students was enjoyable and personally rewarding.

\section{Examples of Clinical Design Projects}

\section{Cranioplasty Implant for Improved Fixation}

This design project developed a new concept for a large ( $>2$ inch diameter) cranioplasty implant with improved fixation over existing products. This design used molded bone cement, based on existing products, but added L-shaped metal plates and a degradable bone-ingrowth strip to im-

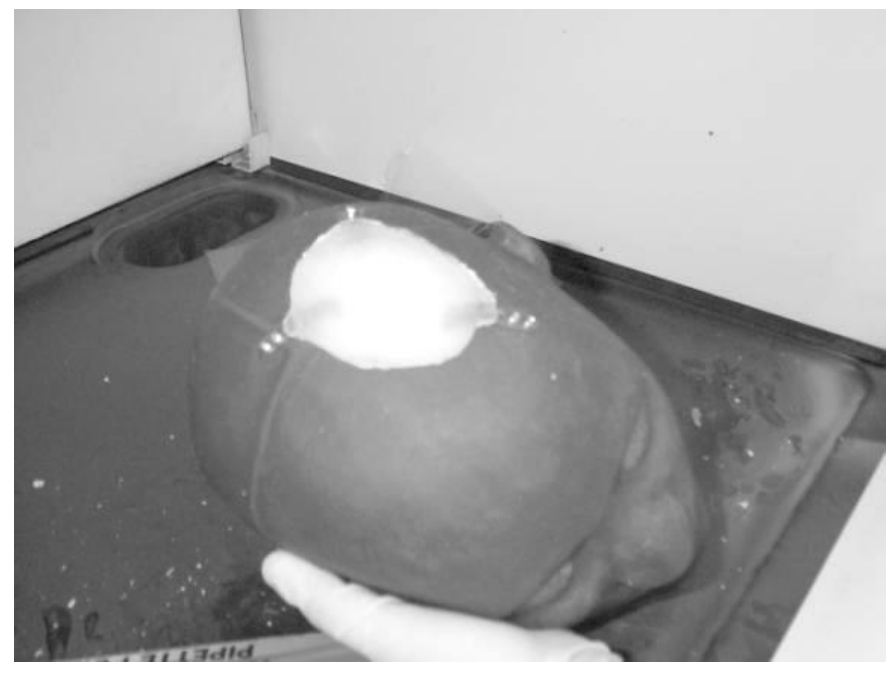

Figure 2. The cranioplasty prototype was fabricated on a headform. prove the fixation to the skull.

Students worked with a neurosurgeon, who met with them at the university once a month during each semester. He developed the concept for this problem based on discussions with the BME faculty teaching senior design. He provided students with specimens of current products used for cranioplasty, including bone cement and metal mesh and titanium screws. He obtained bone cement for students to use for fabrication and testing of prototypes.

Students fabricated their prototypes using sawbones (synthetic bone models) of the 
skull, a headform used for drop-testing of helmets, bone cement obtained from the surgeon, and simulated materials for the L-plates and degradable bone-ingrowth strip. One student worked in a helmet-testing lab, so the design team was able to fabricate one prototype on a headform (see Figure 2) and then drop-test it without a protective helmet. The prototype cranioplasty did not crack on the first drop.

\section{Instruments for Alignment in Unicompartmental Knee Replacement Surgery}

This design project developed two sets of instruments for alignment of the femoral component in unicompartmental knee replacement surgery. The instruments were designed to fit through a small incision for minimally invasive surgery, a new technique currently under development.

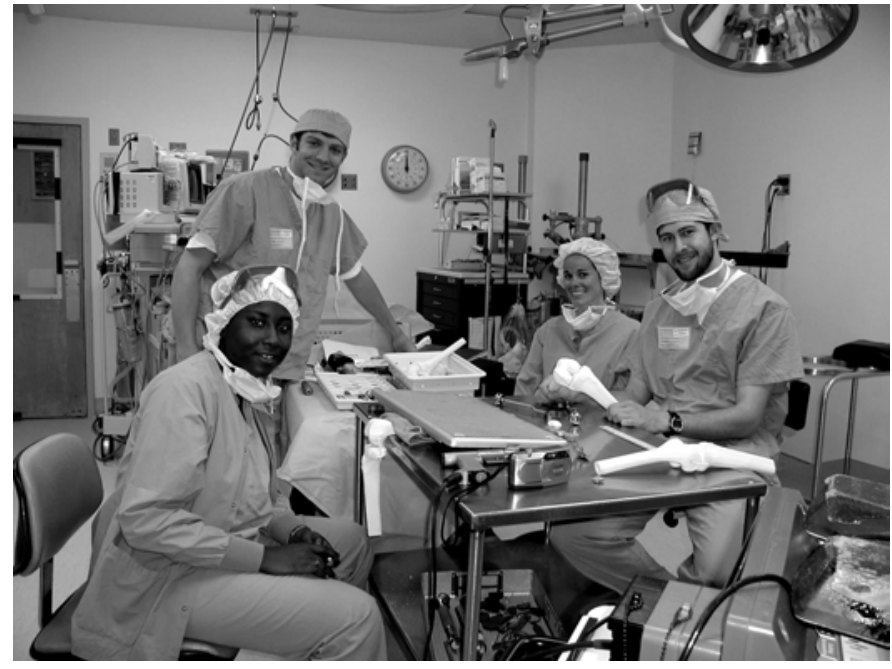

Figure 3. BME design students tested their prototypes using sawbones.
The students worked with the orthopedic surgeon and had the opportunity to observe unicompartmental knee replacement surgery several times. The surgeon met with students at least once a month at one of his offices. He provided them with a training video and printed resources from the implant manufacturer, including step-by-step instructions for the current surgical procedure.

For additional training, students were taught the current surgical procedures using sawbones (synthetic bone models). The surgeon arranged for the local implant distributor to conduct this training. Later the distributor set up another sawbones experiment for the students to test and evaluate their prototypes (see Figure 3). Both times the distributor donated the sawbones, use of surgical saws, drills, and other instruments, and the time of his sales staff to support the design project. The distributor also made current surgical instruments available to students for measurements, sketches, and demonstrations during oral presentations. A sales representative attended the final presentation made by the design team at the end of the Spring semester.

The final engineering drawings were provided to the surgeon, who sent them to the implant manufacturer to have real prototypes made for his own use in surgery. The orthopedic surgeon was so pleased with this design project that he was enthusiastic about volunteering as a technical advisor for a second year.

\section{Instruments for Minimally Invasive Total Knee Replacement Surgery}

The second design project with the orthopedic surgeon is currently underway to develop smaller instruments for total knee replacement surgery. The purpose is to develop minimally invasive surgery, where the incision length is greatly reduced from its current length of about 11 inches. 
The surgeon is providing similar resources to the students for this design project, and they are working with the same implant manufacturer and distributor. Students began by watching a training video and reading printed instructions on the current surgical procedure. Then they were taught the surgical procedures using sawbones (synthetic bone models), and had the opportunity to make measurements and sketches of the existing surgical instruments. This year the distributor personally conducted the sawbones training, rather than having it done by his sales staff. He also loaned students the surgical instruments for use during their oral presentation at the end of the Fall semester. Students plan to test their prototypes using sawbones during the Spring semester. Recently a grant was received from the implant manufacturer to provide financial resources for fabrication of the prototypes and for the design team and their faculty advisor to visit the manufacturer and present their final design project results.

\section{Video System for Measuring Canine Stride Length}

This design project developed a system for measuring canine stride length using a video camera and digital image analysis. Stride length measurements were needed to evaluate canine biomechanics during physical therapy. The video system was set up in conjunction with an existing force plate system mounted in the floor.

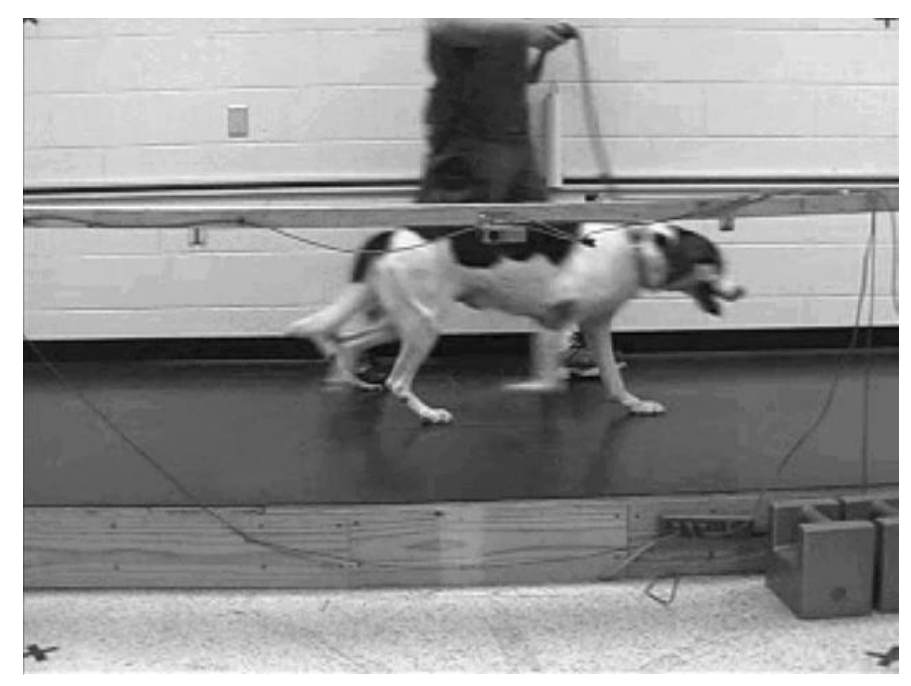

Figure 4. Measurements of canine stride length were made using the prototype video system.
Students worked with the veterinary orthopedic surgeon and other staff at the UT College of Veterinary Medicine. The surgeon met with them at least once a month at his office or laboratory. He provided references on stride length measurements and video systems used at other veterinary biomechanics laboratories. He provided video equipment, the force plate laboratory, canines for evaluation, and funds for purchasing necessary supplies and equipment.

Students assembled a digital video and image analysis system and calibrated it for stride length measurements over the force plate. Then they tested the system by making measurements on a series of canines (see Figure 4).

The veterinary orthopedic surgeon was very pleased with the results of this design project and volunteered as a technical advisor for a second year. He used the system for demonstrations during a visit by other veterinary professionals, with assistance from one of the students. This student then decided to pursue graduate studies in engineering with the veterinary surgeon.

\section{Pedaled Dog Cart for Continuous Passive Motion Therapy of Canines}

The second design project with the veterinary orthopedic surgeon is in progress, to develop a pedaled cart to provide continuous passive motion therapy for canines. The dog cart will be used 


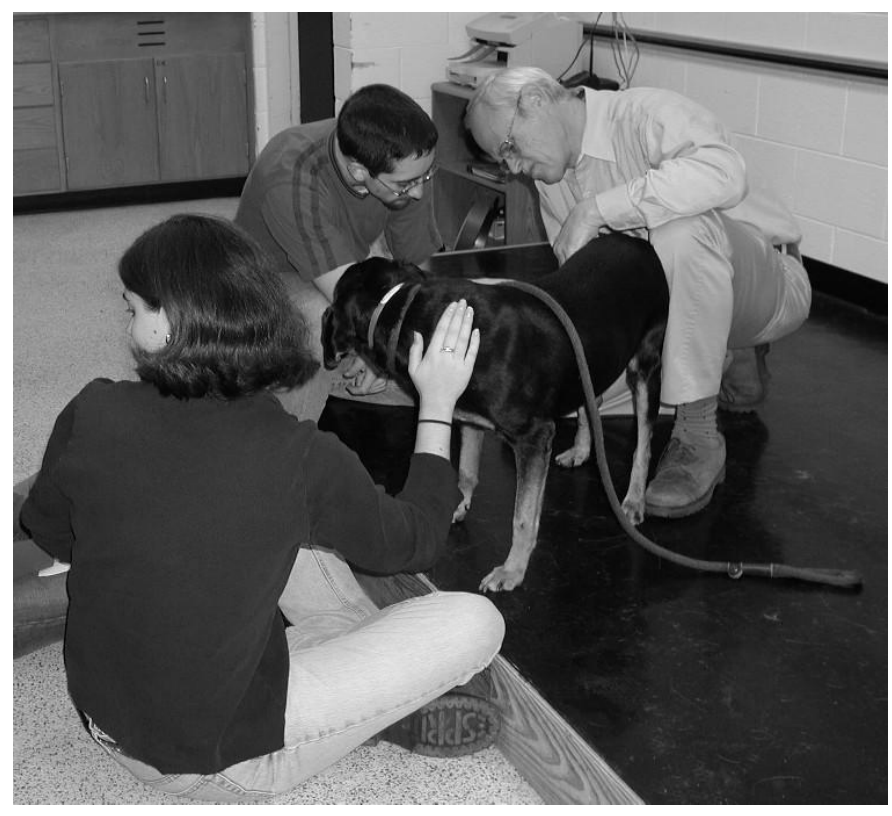

Figure 5. The veterinary surgeon, Dr. Weigel, made canine measurements with BME design students. on a treadmill for physical therapy of dogs with flexibility problems in their stifle (knee) joint(s) on their hind leg(s). The surgeon is providing similar resources for this design project. Students worked with a veterinary physical therapist and were assigned a specific canine for the project. They were loaned a video on canine biomechanics and locomotion and were given references related to their design problem. They have access to a treadmill used for canine physical therapy and the video equipment in the force plate laboratory. The Veterinary Hospital will provide a dog cart for the students to modify in fabricating their prototype.

Students have video taped their canine subject to measure his stride length and joint angles during walking, using the video system developed the previous year. They made biomechanical measurements of the bone lengths in his legs (see Figure 5), and measured the joint angles at his limits of flexion and extension. This data was used in selecting and evaluating design alternatives.

\section{Conclusions}

Recruitment of clinical medical professionals as technical advisors was successful in developing high-quality senior BME design projects. These professionals were helpful in recommending and supporting BME design projects, even when their time involvement was limited. They made three major contributions to the design projects. The first contribution was the motivation they gave to BME students to put extra effort into the design projects. The second contribution was the clinical resources that were provided through their assistance. The third contribution was the real-world feedback provided on design concepts - giving students practical understanding of the clinical issues that must be addressed (separately from the engineering issues) for a successful biomedical product.

\section{Acknowledgments}

The authors would like to thank Dr. Harold Cates, Jr., Dr. Joel Ragland, and Dr. Joseph Weigel for volunteering their time and expertise to serve as technical advisors to senior BME design teams at The University of Tennessee.

\footnotetext{
Bibliography

${ }^{1}$ ENGINEERING ACCREDITATION COMMISSION, 2002-2003 Criteria for Accrediting Engineering Programs, Accreditation Board for Engineering and Technology, Inc., Baltimore, MD, 2002.
} 